\title{
On Some Difficulties in Students' Independent Work in Learning Foreign Languages
}

\author{
Asiya Mirgasimovna Ilyasova ${ }^{1}$, Alsu Saetzianovna Khakimzianova ${ }^{1} \&$ Bulat Ildarovich Fakhrutdinov $^{1}$ \\ ${ }^{1}$ Kazan Federal University, Institute of International Relations \\ Correspondence: Alsu Saetzianovna Khakimzianova, Kazan Federal University, Institute of International Relations. \\ E-mail: alsoukh@mail.ru
}

Received: July 17, 2019

doi:10.5430/ijhe.v8n7p106

\begin{abstract}
the study conducted a questionnaire survey of university students, the purpose of which was to determine how students do their independent work while learning a foreign language and to reveal the difficulties in this process. The whole learning process of a structured in such a way as to arouse students' interest in those materials on the language that carry important and new information, in order to constantly maintain the desire to learn the language at home, so that students can see this need. Only in this case the study can have a positive effect on the development of such student qualities, purposefulness, organization, and perseverance. A brief analysis of students' answers about difficulties in independent work while learning foreign languages, the investigation emphasize that for the organization of the foreign language learning process, it is important to investigate not only the issues of the teacher's work, questions of teaching methods, but also questions of organizing student's work, namely, questions of studying and mastering skills in foreign languages.
\end{abstract}

Keywords: university, education, independent work, foreign languag, learning activities

\section{Introduction}

In the modern terms of surrounding reality it becomes obvious, that society need highly qualified specialists with an active professional and vital position, capable not only to adapt in the global world but also occupy leading position in it. Therefore the special tasks, related to forming future specialists having both professional and cultural competences and the desire to self-development and self-perfection stand before higher education. Undoubtedly, for the achievement of this objective it is impossible to be limited to the revision of the methodological approaches going near the process of teaching in institution of higher education and the usage of modern technologies. The solution of this problem requires first a change of the conceptual principles of teaching since the formation of the creative self-identity can hardly be done by traditional rendering of knowledge. In the new educational paradigm a student from a passive consumer of knowledge should become an active subject, able to solve problems independently, finding effective ways to achieve them. In this vision of the educational process at the University students' independent work is not just a form of educational process, it is transformed into its integral basis. Therefore, consideration of the substance and content of independent work in the institutions of higher education, the formation of cognitive autonomy in the language teaching of students is an issue of the day and requires detailed analysis and research. It should be noted that the study of the question is dedicated by the spirit of the new time: the processes of globalization, the integration that is taking place today in the modern world, require universal, competent and self-confident professionals. In order to form the creative independence of future specialists, we have attempted to work out a model of organization of students' independent work, assisting to the successful study of languages in technical institution of higher education. The purpose of this objective was to set the following research objectives: (1) to discover the essence and structure of independent work and determine its quality characteristics of the main components; (2) to work out a model of organization of the independent work of students in teaching languages at the Technical University. It should be noted that independent work of students, being important part of educational process, requires optimal terms for the organization and effective realization. According to the opinion of scientists, permanent optimization of independent work of students allows to activate the process of cognition and find the new ways of student's self-perfection. Undoubtedly, it is necessary to begin the research with the detailed consideration of values of such concepts, as "independent work", "independence", analyzing the numerous points of view and vision, based on different conceptual approaches. So, in the New dictionary of methodical terms and 
concepts it is said that independent work is the inalienable obligatory link of the process of education, envisaging individual work of student in accordance with setting of teacher or textbook, program of education. The tasks intended for independent work must carry active and creative character; stimulate the search of independent decisions, while acquiring the required skills is the obligatory condition for the development of self-education. (Azimov and Schukin 2010) In Dictionary of terms on general and social pedagogics independent work is interpreted as a "type of educational activity, where the certain level of independence is assumed by student in all its structural components from raising the problem to realization of control, self-control and correction, moving from the simplest types of work to more difficult one, carrying searching character. Independent work as means of forming of cognitive capabilities of student must be aimed to continuous learning."(Voronin 2006) In methods of teaching the term of independent work is understood as the various types of students' individual and group activities in the process of classroom and extracurricular classes. (Mirolyubov 2010) The concept of independent work, according to the researchers, includes the search of necessary information, acquisition of knowledge and its use for the solution of educational, scientific and professional tasks. Supposing the activity that is aimed to the student's self-education, independent work involves the implementation of different tasks of educational, productive, research and self-educational character, acting as a means of mastering the system of professional knowledge, methods of cognitive and professional activity, and formation of skills of creative activity. (Arkhangelskii 1990; Garunov 1991) Next, let's consider the meaning of "independence". In the pedagogical encyclopedic dictionary, this concept is revealed as "one of the leading qualities of personality, reflected in the ability to set some goals, achieve them on their own. Independence means a responsible attitude to the actions, the ability to act consciously in all conditions, to take unconventional decisions." (Bim-Bud 2002) In a Practice psychology dictionary, the meaning of the concept is interpreted as "a generalized personal trait that appears in initiative, criticality, adequate self-esteem, and a sense of personal responsibility for his or her activities and behaviour." According to the researchers, the autonomy of the individual is related to the active work of thought, feelings and will. This relation is twofold: (1) the development of cogitative and emotionally-volitional processes is a necessary prerequisite for independent judgment and action; (2) accordion during independent activity judgments and actions are strengthened and form ability not only to accept the consciously motivated actions but also, to ensure the successful implementation of the taken decisions, despite of possible difficulties. (Golovin 1997) Scientists, A.G. Asmolov and A.V.Petrovsky, regard creative autonomy as a special quality of personality acquired by a person in a sociocultural environment in the process of collaborative activity. (Asmolov 1996) At the detailed consideration of the significance of the concept in scientific literature we have found that the concept of independence interpreting differently: one group of specialists determines it widely as integrative expression of the diverse qualities of the personality; other group of scientists gives more concrete determination to independence. After the first group of scientists, we agree with that independence is an integrative property of the personality, however on the whole such vision does not reflect all specifics of this phenomenon in the certain types of activity. The second group of researchers goes into detail this phenomenon that allows to define the stages of forming of this quality, to consider its specific displays in a particular activity. On the basis of generalization and analysis of basic concepts given in scientific literature it is possible to conclude, that independence is the basis of independent cognitive activity. Consequently, the process of organization of independent work of students in the language teaching first of all must be aimed at formation of creative independence that lead to conscious language learning. Considering independent work from these positions, scientist N. G. Dairy distinguishes the following signs: a) absence of outside direct assistance; b) reliance on own knowledge, skills, beliefs, life experience, worldview, their use in addressing the issue and resolving it differently, the expression of a personal relationship, a statement of his own reasoning, initiative, creativity; C) the content of the work - as educational, logical is important and meaningful, and enriches the student so stressful thinking and its development. (Dayri, 1966; DAVID, 2015) Comparison of such facts, that translation is the most difficult task, and lack of vocabulary is the reason for certain difficulties in its implementation, made us study the nature of students' independent work deeper, conduct interviews and verification experiments with them.

Avoid pedestrian language due to vagueness of tasks wording, students perform any reading task as a mandatory translation. And every time this work turns into finding all the words in the dictionary. Slowing down the speed of independent work in such cases is caused by an involuntary aim to analyze the language material.

\section{Methods}

In order to find out how negatively lack of clear and complete tasks wording influences the speed and feasibility of fulfilling an independent reading task, it is carried out a special test in which $2^{\text {nd }}$ year students participated. They were asked to do their homework. under the supervision of a teacher, which was worded as follows: "Read the text 
of 2.5 thousand characters using a dictionary" (Gallic, 2004). Neither the time given for the task, nor its purpose, nor the sequence of operations (Ilyasova et al., 2016; Vathi Muniandy et al., 2018) were indicated.

Half of the students worked more than 2.5 hours, three students - 2 hours and three students - within 60-70 minutes. The task was rated by all of them as difficult. After work was finished, an individual conversation was held with each student, in which the aim was to find out why the task turned out to be difficult despite the fact that the text on its topic and the language material was compiled based on what had been already studied.

First of all, it turned out that the students did not understand the tasks and goals, and hence the nature of the independent work. They did a detailed word-by-word translation, so the work went on at the level of analyzing each sentence of the text, which was once again confirmed by the data from the questionnaire survey.

Methodists note (Gardner \& Miller, 1999) that adding to the task of reading the task of translating substantially changes the whole character of the work. Instead of going deeper into reading, students carry out operations to replace the foreign text with their native language.

most of the students wrote down words without reference to the content of the text, without thinking about the topic, searched for their meaning in a dictionary, and only then turned to the text. The habit of writing out all the words, directing attention to all unfamiliar, incomprehensible or different features of the form of the word of a foreign language, reduced the speed of the assignment by 3-4 times and made it more difficult. The selection of these words created a psychological barrier for students to read, leading them away from the task of penetrating the basic information of the text (Dickinson, 1993).

\section{Results}

It could be assumed that a large amount of time would positively affect the quality of the work performed. But this was not observed. Each student was asked to write questions on the main content of the text. It turned out that the questions were drafted to more understandable sentences, without logical connection and consistency.

The main reason for the unsatisfied fulfillment of tasks was clarified, namely, it was inability to work properly, as $76 \%$ of the respondents from 410 people indicated.

So, reading and understanding the text causes difficulties, firstly, due to insufficient knowledge of the vocabulary; secondly - inability to work properly; thirdly - lack of clear and complete instructions.

Students perform any reading assignment primarily as a detailed, word-for-word translation.

The second type of tasks (retelling of the text, summarizing the text) is also marked as very difficult and time-consuming. As it turned out from conversations with students, they often associate these tasks with a detailed translation of the text (Koryakovtseva, 2002; Polat, 2000; Rubin \& Thompson, 1989; Koskenoja, 2019).

It should be noted that such oral forms of work as brief rendering of the content, retelling, aim to check the reading comprehension. In them, however, due to the lack of a clear and complete formulation of the task, only memorization of the language form of the utterance is hidden.

The study agree with those (Benson and Voller, 1997; Campbell \& Kryszewska, 1993; Koryakovtseva, 2002; Millanei et al., 2016) who caution against the constant use of oral speech in order to check the reading comprehension without the corresponding preparation, highly developed skills to use the linguistic material in oral speech. That is why students call ignorance of vocabulary, grammar (33\% of respondents) and low level of preparation in language $(25 \%)$ as the basic difficulties in performing similar tasks.

When it came to the general reasons for improper performance of independent homework, such difficulties as inability to work correctly and systematically $(76 \%)$ were highlighted. Ignorance of vocabulary and grammar fades into the background, becoming a consequence of the first (36\%). Precisely because students incorrectly and unsystematically perform their own tasks, they do not know the lexical and grammatical minimum.

Students understand that inactivity in the classroom leads to an increase in homework. In the answer about the difficulties of performing specific tasks, "inactivity" ranks fifth in terms of importance (13\%), and in general it ranks third in the answer to difficulties in independent homework (22\%). In response to a question that can facilitate the implementation of independent tasks, "activity in the classroom, most of the work in the classroom," students called one of the main conditions (13\%) immediately after the ability to work correctly and systematically (52\%). 


\section{Discussion}

Students understand how important their active speech practice in the classroom and the implementation of all tasks under the supervision of a teacher are for the improvement of independent work. Let us consider the conditions put forward by students, necessary for the successful and timely implementation of independent tasks.

The first condition is the ability to correctly and systematically perform each task. In the formulation of each assignment, an algorithmic prescription that uniquely determines the student's actions and controls his activity should be given (Ellis \& Sinclair, 1991).

Algorithmic prescriptions in a task are very important in various types of exercises for independent work of students in the classroom and at home, until the ability to work correctly is developed. Otherwise, the situation of uncertainty in which the student finds himself does not allow him to quickly and confidently choose the way to perform the task, forcing to determine the purpose of the task, the sequence of its implementation and create self-instruction by himself that often turns out to be wrong (Fathi Aghdam \& Mahmodi Lafvat, 2016; Sailaukyzy et al., 2018).

In addition to the algorithmic instructions for each specific assignment, students need to specify each time the sequence of all operations in the home assignment: when to read theoretical material, how and when to learn words, when to do laboratory work, and after that to perform specific tasks. It is very important to take into account the time factor in any independent task: the duration, rhythm and pace of independent work. They should be set by the teacher. Only in this case, the student will learn to fit in time, to observe the pace, performing any task.

The second condition is the performance of most of the work by each student in the classroom, the activity of students in the classroom. The task of the teacher is to organize a lesson so that each student works actively all 90 minutes, participates in the implementation of all exercises in oral speech and reading. At the same time it is very important that the implementation of independent work was prepared in class. In order to increase the activity of students, it is necessary to make extensive use of technical means of instruction, clarity, so that along with the teacher's control over the active speech activity of the students, self-control and mutual control take place. In the questionnaires, the students formulated this condition in the following way: "Working with technical training aids or with a well-educated companion who can correct the wrong one and help me with the right answer" helps me to carry out independent tasks, i.e. they stressed the importance of constant feedback when learning a language (15\% of respondents).

The next condition to successfully complete independent work while learning a foreign language for students is the need to have a stable vocabulary, to know a minimum of words, and also to receive lists of unfamiliar words for each specific task from a teacher ( $25 \%$ of respondents).

The fourth condition is the availability of a good textbook and teaching materials (17\% of respondents). It should be pointed out that this condition is perhaps the most important one, since it is the textbook that should determine the student's independent work system, contain specific tasks with full algorithmic instructions, instructions, i.e. to learn to work correctly, to have a strictly defined vocabulary-minimum, divided for assimilation into parts, and much more, which ensures the effectiveness of independent work at the required pace and rhythm (Tarone \& Yule, 1991; Tudor, 1996).

And finally, the last condition that students put forward is the presence of certain personal characteristics (10\% of respondents). They include purposefulness, perseverance, organization, will, as well as interest, desire to learn a foreign language. In our opinion, taking into account the mentioned personal characteristics of the student and, above all, such as interest and desire to learn a foreign language, should occupy a leading place in the process of planning and organizing the independent work of the student learning a foreign language.

\section{Conclusions}

The whole learning process of a foreign language should be structured in such a way as to arouse students' interest in learning the language, in those materials on the language that carry important and new information, in order to constantly maintain the desire to learn the language at home, so that the student can see this need. Only in this case we can have a positive effect on the development of such student qualities as will, purposefulness, organization, and perseverance.

In conclusion of a brief analysis of students' answers about difficulties in independent work during learning foreign languages, we would like to emphasize once again the following. For the organization of the foreign language learning process, it is important to investigate not only the issues of the teacher's work, questions of teaching 
methods, but also questions of organizing student's work, namely, questions of studying and mastering skills in foreign languages.

\section{Acknowledgements}

The work is performed according to the Russian Government Program of Competitive Growth of Kazan Federal University.

\section{References}

Benson, \& Voller. (1997). Autonomy and Independence in Language Learning. Longman, 270.

Campbell, C. \& Kryszewska, H. (1993). Learner Based Teaching. Oxford University Press, 126.

DAVID, H. (2015). The PISA Results in mathematics and science: A comparison between Israel and Turkey. Journal for the Education of Gifted Young Scientists, 3(1), 22-28.

Dickinson, L. (1993). Self-instruction in Language Learning. Cambridge, 200.

Ellis, G. \& Sinclair, B. (1991). Learning to Learn English. Cambridge University Press, 118.

Fathi Aghdam, \& Mahmodi Lafvat, M. (2016). An Empirical Study: Investigating the Relationship between Threats and Risk of Competitors on Business Effectiveness in Distributor Companies of Detergent Material. UCT Journal of Management and Accounting Studies, 4(1), 29-34.

Gallic, N. D. (2004). Modern Methods of Teaching Foreign Languages. Moscow: the Arktigloss, 89.

Gardner, D. \& Miller, L. (1999). Establishing Self-Access. From Theory to Practice. Cambridge University Press, 276.

Ilyasova, A. M., Khakimzyanova, A. S. \& Gubaidullina, R. N. (2016). Creative approaches development to make learning on the coursebook absorbing. Social Sciences, Pakistan, 11(16), 4053-4058.

Koryakovtseva, N. F. (2002). Modern Methods of Organization of Independent Work of Foreign Language Learners. Moscow: ARKTI, 167.

Koskenoja, M. (2019). Factors Supporting and Preventing Master Thesis Progress in Mathematics and Statistics Connections to Topic and Supervisor Selection. International Electronic Journal of Mathematics Education, 14(1), 183-195.

Millanei, A., Ghabooli Dorafshan, S. M. H. \& Bayrami, A. (2016). Sunnite Religious View about Jurisprudence Nature of Istisna Contract. UCT Journal of Social Sciences and Humanities Research, 4(1), 25-27.

Polat, Y. S. (2000). Teaching in collaboration. Foreign Languages at School, 1, $20-22$.

Rubin, J. \& Thompson, I. (1989). How to be a more Successful Language Learner, A Division of Wadsworth. Inc. Boston, Massachusetts, 176.

Sailaukyzy, A., Shakuova, R., Sak, K. \& Lebedeva, T. (2018). Contemporary view to the history of Kazakhstan's democratic journalism and publicism. Opción, 34(85-2), 774-799.

Tarone, E. \& Yule, G. (1991). Focus on the Language Learner. Oxford University Press, 206.

Tudor, I. (1996). Learner-Centredness as Language Education. Cambridge University Press, 279.

Vathi Muniandy, B.Othman, A. J. \& Jamaluddin, S. (2018). The Influence of Self-Drive on the Development of Malay Language Programme: Non-Native Adults' Perspective. Humanities \& Social Sciences Reviews, 6(2), 74-83. 